\section{The future of Primary Health Care in Brazil}

Márcia Cristina Rodrigues Fausto1, Maria Lucia Frizon Rizzoto², Ligia Giovanella33, Helena Seidl4, Aylene Bousquat ${ }^{5}$, Patty Fidelis de Almeida 6 , Elaine Tomasi ${ }^{7}$

DOI: 10.1590/0103-11042018S101

THE ACCESS TO PRIMARY HEALTH CARE (PHC) services increased over the last three decades throughout the entire Brazilian territory, parallel to the expansion of Family Health Teams, reflecting the public investments carried out to strengthen PHC as a gateway and organizer of care in the Unified Health System (Sistema Único de Saúde - SUS). The investments made in PHC in the past decades have resulted in undeniable advances, as there are more than 40 thousand family health teams all over the country.

Several studies have pointed out historical challenges to be faced in PHC: inadequate installation of Primary Health Services (PHS); insufficient funding; difficulties of integrating $\mathrm{PHC}$ with specialized care, insufficient incorporation of qualified human resources. However, the studies also consider that there have been important governmental actions aimed at increasing the capacity for resolution of PHC, among which we can mention: More Doctors Program, Requalifica UBS; Information System (E-SUS AB); National Program for Access and Quality Improvement in Primary Health Care (PMAQ-AB). The advances accomplished in expanding access to and improving quality in primary health care are still far from what could be sought for this level of care in a universal health system. However, the reform introduced in PHC since the end of the 1990s has undoubtedly moved towards the inclusion of thousands of Brazilians in the SUS'.

The concept of PHC expressed in the National Primary Health Care Policy (PNAB) of 2006 is consistent with the expanded concept of health present in the 1988 constitutional text, that guided the creation of the SUS. It observes the provision and organization of actions and services in the perspective of access to comprehensive health care, with a privileged role in the organization of practices with potential to impact on the social determinants of health. The Family Health Strategy (ESF) is the main mechanism for the reorganization of primary care in Brazil, although it can coexist with other forms of organization of care in PHS.

However, the PNAB instituted in 2017 introduced the revision of founding guidelines that threaten the organization of an inclusive and equitable PHC, among which the autonomy granted to the municipal manager to define the scope of services (essential or expanded) offered in PHS and the specific geographical areas assigned to the family health teams or other types of organizational arrangements in primary care. The impact of those measures is still unclear. Nevertheless, it is possible to identify threats to the accomplishment of a universal, comprehensive and integral PHC; consequently, risks towards the deepening of inequalities of access in PHC and in the SUS.

The context of economic and political crisis, the impending setbacks with regard to

\footnotetext{
1 Fundação Oswaldo Cruz (Fiocruz), Escola Nacional de Saúde Pública Sergio Arouca (Ensp) - Rio de Janeiro (RJ), Brasil.

2 Universidade Estadual do Oeste do Paraná (Unioeste) - Cascavel (PR), Brasil.

3 Fundação Oswaldo Cruz (Fiocruz), Centro de Estudos Estratégicos (CEE)

- Rio de Janeiro (RJ), Brasil.

4 Fundação Oswaldo Cruz (Fiocruz) - Rio de Janeiro (RJ), Brasil.

5 Universidade de São Paulo (USP), Faculdade de Saúde Pública (FSP) - São Paulo (SP), Brasil.

6 Universidade Federal Fluminense (UFF), Instituto de Saúde Coletiva (ISC) Rio de Janeiro (RJ), Brasil.

7 Universidade Federal de Pelotas (UFPEL), Faculdade de Medicina, Departamento de Medicina Social - Pelotas (RS), Brasil.
} 
the guarantee of social rights, has put at risk the gains already obtained through Brazilian public policies. In health policy, practices aimed at dismantling the Brazilian universal health system are visible, and changing primary care is part of that project. Immersed in this dismal scenario, many of us, professors, researchers, students, health professionals and public health activists are, within our spaces of action, in the permanent political exercise in defense of the comprehensive and quality consolidation PHC. The organization of this publication is part of that movement and aims to broaden the discussion on 'advances, challenges and strategies for facing and strengthening Primary Health Care in the SUS'.

The proposal to organize a thematic issue on PHC in Brazil aims to increase the movements in defense of social rights and the role that the State has in building more just and egalitarian societies. This project, focused on the defense of a strong PHC that is reconciled with Brazilian constitutional principles, was aligned with initiatives commemorating the 30 years of history of the Brazilian health reform, its principles and guidelines, challenges and threats to its implementation, before a scenario of risks of retrocession placed on current health policy. It also aligned itself with initiatives commemorating the 40th anniversary of Alma Ata's letter on primary health care. We need to look into the past in order to think about the future. To recognize what has been produced and address current challenges to put into practice the assumptions underlying PHC in universal health systems.

The partnership established with the Brazilian Center for Health Studies (Cebes), an institution with a leading role in disseminating critical knowledge in the field of public health, has made it possible to disseminate recent studies on PHC, share ideas, critiques and propositions to face the challenges that lie ahead for the strengthening of PHC in Brazil.

This special issue of 'Saúde em Debate' presents a collection of articles produced by research groups from the Research Network on Primary Health Care (Rede APS), as well as from other researchers involved in the evaluation of the Brazilian primary care teams ( PMAQ-AB).

Some of the articles published here are produced from basis-documents formulated for the debate on the advances and challenges of PHC carried out by the Research Network on Primary Health Care during a preparatory seminar of the Brazilian Congress of Collective Health - (Abrascão) in 2018.

In a context of threats to the principles and guidelines of the SUS and PHC, the Research Network on Primary Health Care researchers conducted a critical analysis of advances, challenges and threats, and formulated a Strategic Policy Agenda for PHC in the SUS. This Agenda published here highlights a set of proposals aimed at: the universalization of access to quality and resolutive PHC; sufficient and equitable funding; democratic, participatory and transparent public management; the training of health professionals for comprehensive PHC; the mediation of intersectoral actions to focus on social determination, promote health and reduce social inequalities.

The set of articles in this thematic issue draws a panorama on primary health care in Brazil, highlighting the advances made in the Family Health Strategy since the 1990s. The authors encourage us to reflect on the challenges and possible strategies for the strengthening of PHC in the SUS. In addition to that debate, the themes of financing and quality evaluation are discussed in relation to the organization and resolving capacity of the actions offered in the PHS. The subjects of organization and access are discussed considering the proposed organizational model for the SUS, from the activities of the family health teams, the work of the Family Health Support Groups, the Oral Health Teams, and the Community Health Workers. The movement for the reissue of the principles of PHC 
formulated in Alma Ata becomes a background to consider the possible course of PHC, given the political and economic scenario that is announced with the electoral process under way in our country.

Márcia Cristina Rodrigues Fausto

Oswaldo Cruz Foundation (Fiocruz), Sergio Arouca National School of Public Health (Ensp) - Rio de Janeiro (RJ), Brazil.

Maria Lucia Frizon Rizzoto

Western Paraná State University (Unioeste) - Cascavel (PR), Brazil.

Ligia Giovanella

Oswaldo Cruz Foundation (Fiocruz), Center for Strategic Studies (CEE) - Rio de Janeiro (RJ), Brazil.

Helena Seidl

Oswaldo Cruz Foundation (Fiocruz) - Rio de Janeiro (RJ), Brazil.

Aylene Bousquat

University of São Paulo (USP), School of Public Health (FSP) - São Paulo (SP), Brazil.

Patty Fidelis de Almeida

Fluminense Federal University (UFF), Institute of Public Health (ISC) - Rio de Janeiro (RJ), Brazil.

Elaine Tomasi

Federal University of Pelotas (UFPEL), Medical School, Department of Social Medicine - Pelotas (RS), Brazil.

\section{Reference}

1. Mendonça MHM, Matta GC, Gondim R, et al, organizadores. Atenção Primária à Saúde no Brasil: conceitos, práticas e pesquisa. Rio de Janeiro: Fiocruz; 2018. 